\title{
A Morpho-syntactic Analysis of Modal Verbs in Iraqi Dialects: A Comparative Study
}

\author{
Amthal Mohammed Abbas, Sarab kadir Mugair* \\ College of Basic Education, University of Diyala, Iraq \\ Corresponding Author: Sarab kadir Mugair, E-mail:sarabkadir@gmail.com
}

\section{ARTICLE INFO}

\section{Article history}

Received: August 18, 2017

Accepted: October 16, 2017

Published: January 05, 2018

Volume: 7 Issue: 1

Advance access: December 2017

Conflicts of interest: None

Funding: None

\begin{abstract}
This study is an attempt to investigate and analyze the linguistic forms of modal verbs in three Iraqi dialects. These modal verbs are "can", "will" and "must" and the dialects under study are Musiliyah that is spoken in Mosul province in the north of Iraq, Baghdadiyah that is spoken in Baghdad city in the middle of Iraq and Basriyah that is spoken in the city of Basrah in the south. The study adopts the descriptive and comparative techniques of James' theory (1998) to analyze the data. The present study aims to investigate and analyze three modal verbs in three Iraqi dialects. It tends to share the same views of Ma'ruf (2011:24) and James (1998:19) who state that nations' dialects can be fruitful which in turn can enrich their mother tongue, in disagreement with Lakoff (1972:) who argues that dialects may hinder their mother tongue which eventually can be fuzzier than of great help. The findings of the present study reveal that, in a way or another, speakers of IDs can use different kinds of clauses to convey the general and predicative meaning simultaneously. Dialects can help speakers of IDs reinforce their specificities and preferences, i.e., dialects strengthen their ability to create new words, which at long last, enrich their mother tongue. The analysis of the present study proves the usability of Ma'ruf's (2011) and James' (1998) standing regarding the dialects. Contrarily, the analysis also shows that Lakoff's views (1972) are not, to an extent, objective, i.e. her views are relative.
\end{abstract}

Key words: Dialects, Structure of Arabic Modality, Iraqi Dialects

\section{INTRODUCTION}

People of the same countries speak, almost, the same language. It is commonly believed that language may differ when there is systematic differences between two speech communities which may, to some extent, reflect two dialects or, let's say, two languages. This tend to impose an idea that different groups of people, like individual speakers, that speak the same language but, eventually, they speak it differently.

Arabic, like all languages, is spoken by a large number of people, specifically, in Arab countries, and, in turn, it is spoken in each country differently. That's why there are a number of dialects since there are regions and cities. Then, to investigate the dialects, spoken and written, is an outstanding task. Thus, some of the examples about the data which are supposed to be considered in this study are taken from daily life, and since linguists usually give greater authority to the written rather than the spoken word, the present study will deal with the written form of Arabic language; the Iraqi dialects which vary from city to city or even from village to another.

Iraqis currently make use of the non-standard forms (colloquial) when writing in their everyday life situations. That's why this study takes its importance of recording the varieties and changes that Arabic language undergoes. Additionally, when making such a record, one can make a judgment of the extent of how a language diverges and / or converges in the area of varieties.

However, scholars like Nickel (1971:10) and Fisiak (1981:21) state that a systematic comparative study is sort of studies that can be used to analyzes the differences and similarities among languages which was clearly recognized toward the end of $19^{\text {th }}$ century and the beginning of $20^{\text {th }}$ century. Further, Fisiak (ibid:21) suggests the term 'Comparative or Contrastive linguistics' which is defined as " a sub-discipline of linguistics concerned with the comparison of two or more languages or subsystems of languages in order to determine both the differences and similarities between them".

However, James (1998:34) states that we use the term 'comparative study or analysis' if we want to compare two or more different characteristics of the same language and / or different languages. Following this idea further, Ma'ruf (2011:24) argues that every country has its own culture and, when the culture is deeply analyzed, we will see that a country's culture is sometimes similar or equal to another's and sometimes not. For example, Iraqi language is genealogically related to Semitic language, i.e., Arabic language that is geographically spoken in the West Asia.

To Ma'ruf (ibid), every language has its structure, meaning and function. The structure of Iraqi dialects (IDs) and 
Iraqi language (IL), as he believes, has similarities and characteristics of each. Anyhow, structural equation IDs and IL can be revealed by the comparative method, while the structural characteristics of IDs and IL can be investigated by the contrastive method.

However, one of the most fundamental components of the characteristic structure of language at the level of the sentence is modality. To Matthews (2005: 225), Arlotto, (1972:11) and Wided (2010:25), the term modality is defined as "category covering either of a kind of speech act or the degree of certainty with which something is said". In the same respect, Steel et al., (1981:) state that modality can generally be indicated by the following: possibility or the related concept of permission, probability or the related concept of obligation, certainty or the related concept of requirement.

Obviously, Harbi (2011:2-3) and Holes (1995:42) classify Arabic modalities into 7: First, (yurïdu / aräda) 'want, wanted, would like'; second, (yastațị / istațị) and (yaqdir / qadir) 'can, could, be able to'; third, (yumkin / mumkin / yuhtamal / muhtamal / qad) 'may/might/could/be probable'; fourth, (jäyiz / yajüz / yustahïl / impossible) 'can /could be / possible / impossible'; fifth, (Sawfa) and (sa-) 'will / shall / be going to'; sixth, (yanbaghi and yajib) and (labud) 'should / must / ought to / be obliged to / have; and seventh, (yalzam) 'be obliged to / should / have to'.

That way, in the next section, the present study will analyze the linguistic forms of finite verb of modality 'astațic' / 'can' in three Iraqi dialects Musliliyah, Baghdadiyah and Basriyah spoken in three different Iraqi regional cities: Mosul (north), Baghdad (middle) and Basra (south) respectively.

\section{ARABIC MODALITY (AM)}

In fact, most of Arabic varieties including the Iraqi one have great similarities concerning modality. In short, this study focuses on the Arabic modality in general and the modal verbs "can", "will' and 'must' in particular representing the sample of the study. Ma'ruf (2011:25) argues that modals as a grammatical class do not exist in Arabic. Their meanings are indicated by unmodified verbs, particles and prepositional phrases. For example, "can" can be written in Arabic as a prepositional phrase. Look at the following:

1. fi istita'ati

in my capacity

as in:

2. I can swim well.

fi istita'ati? an? assbih jayydan

in my capacity that I swim well

"Can" may also be represented by the verb / yastati؟ / can, to be able:

\section{3. ?astati ? an ?assbih jayydan}

I am able to swim well

However, Safi (2001: 9-11) states that Arabic modality in Arabic language (AL) has three types of modalities. First, Arabic modal auxiliaries (AMA), which كاد / käda / 'nearly',

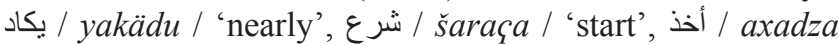
/ 'start'. Second, finite verbs of modality (FVM), تشنطيع / tastatïl / 'can', يجوز / yajüzu / 'may', يحنمل / yuhtamil / 'maybe'. Third, non-verbal modality (NVM),

\section{4. امها باسم سميت}

/ sumiyat Bismi ummihä

'she was called by the name of her mother' القو انين أن تطيع عليك يجب

5. / yajibu çalaika an tațǐca 'l-qawänïni

'You must obey the rules'.

Likewise, Alkhuli (1982:27) points that the auxiliary verb in Arabic term is musäçidun 〈ready〉. Musäçidun is the nature of words or verbs. Auxiliary is the nature of the word or verb that acts as an auxiliary verb; verbs which help the main verb, such as may, can and will. Sometimes auxiliary verbs present the meaning of obligation, possibility, futurity, ability, past, sustainability, and so on. Alkhuli (ibid:95) argues that finite verb in the Arabic term is ficlun mahdudun. Fiçlun mahdudun is a perfect or imperfect verbs. Finite is a perfect verb or imperfect verb that is not used for the whole persona pronouns and nouns or verbs that serve to connect mubtada and khabar (subject and predicate) on sentence like: (He is a doctor). In Arabic, it may connect a subject and verb in a verbal sentence (VSO).

Harbi (2011:3) states that the features in the character of modal element of Arabic verbs of saying are as follows: First, the modal of Arabic verb forms are either auxiliary or finite. Second, the modal Arabic verbs such as verbs AL can be an argument (subject) for the verb. Third, for negative particles, modal Arabic verbs may be inserted except [läbud]. Fourth, the Arabic modal verb serves as a non-finite complement. Fifth, for interrogative sentences the modal of Arabic verbs can form sentences with the structure of VSO or SVO.

\section{THE MODEL OF STUDY}

Through his theory "pure comparative analysis", James (1998:35) argues that every naturally used language variety is systematic, with regular rules and restrictions at the lexical, grammatical and phonological levels. Although some scholars especially non-linguists sometimes indicate that some dialects, unusually non-standard ones, don't have any rules, or that they are simply the result of their speakers' laziness and carelessness. Linguists usually give us different views: (a) views on empirical grounds, i.e., dialects always turn out to have regular rules, (b) views on theoretical grounds, i.e., the theoretical reason is that the successful acquisition and use of a language variety in a community of speakers would be impossible if language were not systematic and rule-governed. Thus, If every speaker could utter his or her own words and no rules for pronunciation and grammar; the communication between different speakers would be virtually impossible.

In short, James's model (ibid) reveals that the most fundamental differences or variations within language take place at the following levels: the lexicon (vocabulary), phonology (pronunciation), grammar (morphology and syntax), and usage. To James (ibid), variation can be stylistic, social and regional in its origins, and the techniques that scholars or linguists have used to analyze each level slightly differ.

To analyze the data, James's model is adopted in the present study for the following remarks: (a) to highlight the level 
of language including structure and lexicon, (b) to narrow the object of unit study via classification in some dialect units: words, phrases and clauses, and (c) to apply the results of analysis as a model of learning Arabic-Iraqi - English translation, i.e. James's classifications are relevant to the aims of study.

\section{Theoretical Framework}

As mentioned earlier, James's model helps a great deal to showcast the notion of systematic variety of language. The model will also support this study with the notion of language variation and how this notion is used in interpreting the present data. Furthermore, data is analysed here at the levels: lexicon, phonology and grammar on the assumption that mother tongue language is strongly strengthened through its dialects as the above theory or model discusses the concept of language variety in speech and how this concept is achieved via lexicon, phonology and grammar.

As regard the analysis, James's models, figure 1, is used to analyze the data in the current study on the basis of three levels.

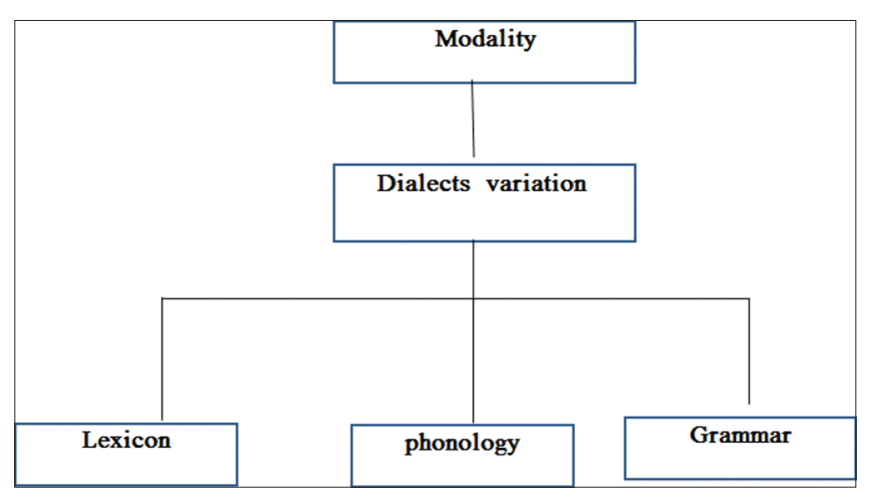

Figure 1. The model of the study

\section{THE LEVELS OF ANALYSIS}

Using the framework discussed in the previous section, modal verbs are analyzed at three levels. In the first level, the researchers focus on the lexis per se to identify the modality patterns in the selected data. Once the patterns are identified, the researchers will attempt to clarify how these patterns contribute to particular meanings and how they facilitate speech interpretation. The second level of analysis focuses on phonology to help the researchers show the differences in pronunciation within and across dialects under study. The third level focuses on the grammatical structures where the modality patterns are found to further explain the meaning of the data. Here, the modal verbs are 'can', 'will' and 'must'.

\section{Lexical variation}

To James (1998: 12) and Saeed, (2004: 57), differences in vocabulary are one category of dialect diversity which people observe readily and comment on quite frequently. They are certainly common enough as markers of the differences between geographical areas or regions. Accordingly, James
(1998:17) and Labov (1968:151) state that lexical differences take a fundamental role in regional dialectology (the study of regional dialects). Thus, lexical differences are given prime coverage.

To this study, lexical differences are not regarded as salient in indicating the speech of different social or socioeconomic classes. They have acted a much smaller role in social dialectology (the study of social dialects), which has concentrated instead on differences in phonology and grammar. They are surely a portion of ethnic differences. Thus, most of these terms are best familiar within the Iraqi speakers community. It is seen that the publicity of Iraqi speakers music and culture, for example, has also made many of them known to teenagers from other ethnic groups, mostly these and other slang terms would, to some extent, be regarded symbols of group culture. However, Iraqi speakers often utter new slang terms as fast as they can. And these terms are still fundamental differences between the speakers of Iraqi dialects. Simultaneously, some words or items, which are uttered as slang, might be part of the informal vocabulary of certain other-groups and gradually of the nation as a whole. For example the modal verb 'can' can be represented by [baaqdil] in Musiliyah, [agder] in Baghdadiyah and [biah] in Basriyah dialects. While the verb 'will' can be represented by the pre- suffixation [Ha-] as in [Haji], 'I will come.' in Musiliyah, while 'will' can be replaced by the word [Raah] in Baghdadiyah. Whereas 'will' can be indicated by both the pre- suffixation [Ha- $]$ and [ $\mathrm{Raah}]$ in Basriyah dialects. As for the verb 'must', it can be indicated by [Alaiik] in Musiliyah, [Lazim] in Baghdadiyah and [YatHatim] in Basriyah. For more examples and details, please see grammatical variation below.

\section{Phonological Variation}

Phonological variation indicates the differences in pronunciation across and within dialects, for example, the fact that people from Mosul may utter "can" like [b-aaqdi-l], i.e., with b, q, and 1, people from Baghdad may utter it like [agder], i.e., with $g$ and $r$, while people from Basra may utter it like [biah], in different ways. Similarly, people from Mosul may pronounce "will" as [Ha-] and "must' like [Alaiik], people from Baghdad may pronounce it like $[$ Raah $]$ and "must" like [Lazim], whereas people from Basra like both Mosul and Baghdad may pronounce "will" like either [Ha-] or [Raah] but they may pronounce "must" like [YatHatim] completely different.

According to James (1998:37), Ibrahim (2007:47) and Dawod, (2001:167), phonological variants are certainly salient as markers of regional dialect. For example, the stereotypical Musiliyah pronunciation of the following is:

6. "I can say to you" as

[?ana baaqdil aqulik.]

Which includes $\mathrm{b}$, and 1 of [aqder]. On the other hand, the stereotypical Baghdadiyah pronunciation is as follows:

7. "I can say to you" as

[? ani agder agulik.]

Which includes g of [aqder], while Basriyah

8. [?ana biah agulik.] 
that includes zero of [aqder]. For more details, please see the section that follows.

The can example is just one instance of a fairly common event via which phonological consolidation in two or more dialects makes synonymous issues (words having the same or nearly the same meaning but different pronunciation). To this study, phonological variation in this way insofar can be central to social variation and stylistic variation as well, and relevant examples are supported in the following part.

\section{Grammatical Variation}

As it is mentioned above, grammatical variation involves two sub-types: morphology and syntax. Morphology indicates the structure or forms of words, referring to the morphemes or minimal units of meaning which include words, for example the morphemes $\{\mathrm{im}\}$ "not" and \{polite $\}$ "polite" in impolite, or the morphemes $\{$ pen $\}$ "pen" and $\{s\}$ "plural" in pens. Whereas, syntax indicates the structure of larger units like sentences and phrases, involving rules for combining and relating words in sentences, for example the rule that is realized in English yes / no questions, auxiliaries must shift to the beginning of sentences, before the subject noun phrase (e.g. Can Tom swim? Opposite to Tom can swim).

Thus, we can find instances of regional variation of both types. For example, the form (or morphology) of the present tense of "can", "will" and "must" can be indicated as [b-aaqdi-l], [Ha-] and [Alaiik] respectively in Mosul, [agder], [Raah] and [Lazim] in Baghdad, and [biah], [Ha-], [Raah] and [YatHatim] in Basra.

Perhaps even more dramatic is the use of "can", "will" and "must" in the following sentences:
People of Mosul may use "can" in declarative clauses like:

9. ?ana baaqdil aqulik.

'i can say you'

'I can say to you.'

Or

10. Hua biyaqdil ysaa'dik.

'he can help you'

'He can help you.'

People of Baghdad may use "can" in declarative clauses as in:

11. ?ani agder agulik.

'i can say you.'

'I can say to you.'

Or

12. Hua yigdir ysaa'dik.

'he can help you'

'He can help you.'

More clearly, people of Basra may use "can" in declarative clauses such as:

13. ? ana biah aglik.

'i can say you.'

'I can say to you.'

Or

14. Hua bih yisaadik.

'he can help you'

'He can help you.'

According to interrogative clauses, people of Mosul may use "can" in interrogative clauses as in:

15. bitaqdil tala'b? anta?

'can-you play you'

Usages of "can" in declarative clauses

\begin{tabular}{lllll}
\hline Examples & Musiliyah & Baghdadiyah & Basriyah & Meaning of 'can' \\
\cline { 2 - 5 } & ?ana baaqdil aqulik. & ?ani agder agulik. & ?ana biah aglik. & able to/capable to \\
'i can say you' & 'i can say you.' & 'i can say you.' & 'I can say to you.' \\
'I can say to you.' & 'I can say to you.' & Hua bih yisaadik. \\
'He can hiyaqdil ysaa'dik. & Hua yigdir ysaa'dik. & 'he can help you' \\
'He can help you.' & 'he can help you' & 'He can help you.' & 'He can help you.' \\
Hum biyaqdalu yila'abu. & Huma yigdarun yila'abun. & Huma bihum yila'abun. \\
'they can play' & 'they can play' & 'they can play' \\
'They can play.' & 'They can play.' & 'They can play.' & \\
\hline
\end{tabular}

Usages of "can " in interrogative clauses

\begin{tabular}{|c|c|c|c|c|}
\hline Examples & Musiliyah & Baghdadiyah & Basriyah & $\begin{array}{l}\text { Meaning of } \\
\text { 'can' }\end{array}$ \\
\hline & $\begin{array}{l}\text { bitaqdil tala'b? anta? } \\
\text { 'can-you play you' } \\
\text { 'Can you play?' }\end{array}$ & $\begin{array}{l}\text { Tgdir tala'b ?anta? } \\
\text { 'can-you play you' } \\
\text { 'Can you play?' }\end{array}$ & $\begin{array}{l}\text { bik tala'b ?anta? } \\
\text { 'can-you play you' } \\
\text { 'Can you play?' }\end{array}$ & able to/capable to \\
\hline & $\begin{array}{l}\text { Biqdil yudrus huwa? } \\
\text { 'can-he study he' } \\
\text { 'Can he study?' }\end{array}$ & $\begin{array}{l}\text { Yigdir yudrus huwa? } \\
\text { 'can-he study he' } \\
\text { 'Can he study?' }\end{array}$ & $\begin{array}{l}\text { Bih yudrus huwa? } \\
\text { 'can-he study he' } \\
\text { 'Can he study?' }\end{array}$ & \\
\hline & $\begin{array}{l}\text { Biyaqdilun yakluun huma? } \\
\text { 'can-they eat they' } \\
\text { 'Can they eat?' }\end{array}$ & $\begin{array}{l}\text { Ygdrun yakluun huma? } \\
\text { 'can-they eat they' } \\
\text { 'Can they eat?' }\end{array}$ & $\begin{array}{l}\text { Bihum yakluun huma? } \\
\text { 'can-they eat they' } \\
\text { 'Can they eat?' }\end{array}$ & \\
\hline
\end{tabular}


Usages of "can" in if clauses

\begin{tabular}{|c|c|c|c|c|}
\hline Examples & Musiliyah & Baghdadiyah & Basriyah & $\begin{array}{l}\text { Meaning of } \\
\text { 'can' }\end{array}$ \\
\hline & $\begin{array}{l}\text { Bitiqdil tiagei bakiir kan } \\
\text { ?ahssan. } \\
\text { 'if could-you come earlier } \\
\text { that it better' } \\
\text { 'If you could come earlier, } \\
\text { it would be better. ' }\end{array}$ & $\begin{array}{l}\text { Law Tgdir tigi man wakit chan } \\
\text { ?ahssan. } \\
\text { 'if could-you come earlier that it } \\
\text { better' } \\
\text { 'If you could come earlier, it } \\
\text { would be better. ' }\end{array}$ & $\begin{array}{l}\text { Law bik tigi man wakit chan } \\
\text { ?ahssan. } \\
\text { 'if could-you come earlier that } \\
\text { it better' } \\
\text { 'If you could come earlier, it } \\
\text { would be better." }\end{array}$ & \multirow[t]{3}{*}{$\begin{array}{l}\text { able to/capable } \\
\text { to }\end{array}$} \\
\hline & $\begin{array}{l}\text { Law biqdil yudrus huwa } \\
\text { amniih kan, shirah halkitib. } \\
\text { 'if could-he study he hard, it } \\
\text { better that he buy this book' } \\
\text { 'If he could study hard, it } \\
\text { would better to buy this } \\
\text { book.' }\end{array}$ & $\begin{array}{l}\text { Law Yigdir yudrus huwa zain, } \\
\text { chan ?ashtarah halkitab. } \\
\text { 'if could-he study he hard, it better } \\
\text { that he buy this book' } \\
\text { 'If he could study hard it would be } \\
\text { better to buy this book.' }\end{array}$ & $\begin{array}{l}\text { Law bih yudrus huwa zain chan } \\
\text { ?ashtarah halkitab. } \\
\text { 'if could-he study he hard, it } \\
\text { better that he buy this book' } \\
\text { 'If he could study hard it would } \\
\text { be better to buy this book.' }\end{array}$ & \\
\hline & $\begin{array}{l}\text { Law biyqdilu yakluun huma } \\
\text { amniih, kan ?ashawu. } \\
\text { 'if could-they eat they, it } \\
\text { was that they still alive' } \\
\text { 'If they could eat well, they } \\
\text { would still be alive.' }\end{array}$ & $\begin{array}{l}\text { Law yigdrun yakluun huma zain, } \\
\text { chan ?ashawu. } \\
\text { 'if could-they eat they, it was that } \\
\text { they still alive' } \\
\text { 'If they could eat well they would } \\
\text { still be alive.' }\end{array}$ & $\begin{array}{l}\text { Law Bihum yakluun huma zain, } \\
\text { chan? ashawu. } \\
\text { 'if could-they eat they, it was } \\
\text { that they still alive' } \\
\text { 'If they could eat well, they } \\
\text { would still be alive.' }\end{array}$ & \\
\hline
\end{tabular}

Usages of "will " in declarative clauses

\begin{tabular}{lllll}
\hline Examples & Musiliyah & Baghdadiyah & Basriyah & Meaning of 'will' \\
\cline { 2 - 5 } & Hajie. & Raah ?ajie. & Raah ?ajie/Hajie. & be going to \\
& 'will I come' & 'will I come' & 'will I come' & \\
& 'I will come. & 'I will come.' & 'I will come.' & \\
\hline
\end{tabular}

Usages of "will " in interrogative clauses

\begin{tabular}{lllll}
\cline { 4 - 5 } Examples & Musiliyah & Baghdadiyah & Basriyah & Meaning of 'will' \\
\cline { 2 - 6 } & Hatigi ?alyuim? & Raah tigi ?alyuim? & Raah tigi/Hatigi ?alyuim? & be going to \\
& 'will come you today' & 'will come you today' & 'will come you today' & \\
& 'Will you come today?' & 'Will you come today? & 'Will you come today?' & \\
\hline
\end{tabular}

Usages of "Must " in declarative clauses

\begin{tabular}{lllll}
\hline Examples & Musiliyah & Baghdadiyah & Basriyah & $\begin{array}{c}\text { Meaning of } \\
\text { 'must' }\end{array}$ \\
\hline $\begin{array}{llll}\text { Alaiik ?an tuqul kul ?al haqiqa. } \\
\text { 'must-you that say-you all the } \\
\text { truth' } \\
\text { 'You must say all the truth.' }\end{array}$ & $\begin{array}{l}\text { Lazim atguk kul ?al haqiqa. } \\
\text { 'must-you that say-you all } \\
\text { the truth, } \\
\text { 'You must say all the truth.' }\end{array}$ & $\begin{array}{l}\text { yatHatim alaik atgul kul ?alhaqiqa. } \\
\text { 'must-you that say-you all the truth' } \\
\text { 'You must say all the truth.' }\end{array}$ \\
\hline
\end{tabular}

'Can you play?'

Or

16. Biqdil yudrus huwa?

'can-he study he'

'Can he study?'

\section{FINDINGS AND DISCUSSION}

Languages vary as a result of place and social setting which is evidently seen in the differences in the Iraqi dialects. These differences imply great changes on the lexical level by having sort of new words which are not part of the standard, on phonological level through having different pronunciation, and on grammatical one via constructing new words, phrases and sentences structures.

The grammatical variation, with non-standard or vernacular variants, seems to be more a marker of social dialects and formal / informal styles than it is of regional dialects. Whether positive or negative, grammatical variables seem to have powerful social marking.

One example at the level of morphology is the addition of the prefix [b-] as in [baaqdil] in Musiliyah. This feature is common in Mosul because people of Mosul are affected by neighboring regions and countries like Syria and Lebanon who always use the prefix [b-] before verbs. 
Contrarily, people of Basra use the word [biah $]$ to indicate the present tense of "can" which is common and accepted in Gulf States like Kuwait, Saudi Arabia, etc. who traditionally use the word [biah] referring to the present tense of "can". One cannot ignore the vicinity of these states to Basrah and their common interconnection and communication.

People of Baghdad, on the other hand, don't have such features, i.e. since they are distant from the above-mentioned influencing factors (countries); they are not affected by them. Some other reasons can be suggested in the case of the dialect spoken in Baghdad may be, to some extent, Baghdadi people are culturally higher than people in other provinces. Like other capital cities elsewhere, Baghdad is, more or less, the place where the leading and notable people live. This gives rise to a belief which reveals that people, like Baghdadis, of high prestige or scientific level tend to speak highly standardized dialect just to show and reflect their status and way of living. That's why Baghdadiyah dialect is the closest dialect, over Iraqi ones, to the standard Arabic. Additionally, one can find a large number of people speaking the standard Arabic due to the existence of prominent universities and institutions. In the same view, a university professor of Arabic tends to speak the standard normally and even his / her students may follow to do so.

One more thing to add is that people of Baghdad are affected by foreign habits of communication taken from frequent travelling abroad. As is known, travelling can, for most, improve the habits speakers may have. Moreover, being the capital, Baghdad city can affect the people who live in socially, scientifically and culturally. Day after day, people evidently undergo changes because of tourism and the cultural movement and exchange in the capital of their country.

Most of the descriptive research which linguists have done on dialects over the past thirty years has focused on its grammar. These examples may appear to be simple lexical items, but they fall under "grammar" rather than "lexicon" because they have grammatical rather than lexical meaning, serving to indicate grammatical relationships rather than possessing semantic content in and of themselves (James, 1998:27).

In the light of the comparative analysis of modal verbs in IDs, the study sums up with the following remarks:

1. The modal verbs "can", "will" and "must" offer a variety of speech preferences to speakers of IDs.

2. The meanings of "can" are conveyed as follows: prepositional phrase such as "baaqdil" in Musiliyah and "biah" in Basriyah dialects, unmodified verb as "agder" in Baghdadiyah. The three regions show great diversity in the area of the modal verb "can" to indicate ability, possibility or certainty, etc.

3. The meanings of "will" are conveyed as adverbial phrases; the prefix "Ha-" in Musiliyah and Basriyah; unmodified verb as "Raah" (going to) in Baghdadiyah and Basriyah dialects. Here, in this respect, the provinces enjoy type of convergence and affinity. People tend to use the same structures though the live in different regions $450 \mathrm{~km}$ away.

4. The meanings of "must" are demonstrated as in the following: prepositional phrase such as "Alaiik" in Musiliyah and unmodified verbs as "Lazim" in Baghdadiyah and
"yatHatim" in Basriyah dialects. Since the three provinces follow different style of showing obligation or advice.

5. The speakers of IDs can use different kinds of clauses to convey the general and predicative meaning of "can", "will" and "must" simultaneously.

6. The present study can, in a way or another, help the speakers of IDs reinforce their specificities and preferences, i.e., it strengthens their ability to create new words which in turn enrich their mother tongue.

7. The analysis of present study proves that the hypothesis of Ma'ruf (2011) and James (1998) regarding the dialects is mostly acceptable in which the dialects of nation help the speakers to enrich their native language or mother tongue language.

8. The present analysis also shows that Lakoff's views (1972) are not, to an extent, objective concerning dialects in that the dialects may hinder the native language, i.e., her views are relative.

\section{REFERENCES}

Alkhuli, M. A. (1982). A dictionary of theoretical linguistics: English-Arabic with an Arabic-English glossary. Beirut: Librairie du Liban.

Arlotto, A. (1972). Introduction to Historical Linguistics. Boston: Houghton Mifflin.

Dawod, M. (2001). Al-Arabiyyah wa-ilmu 'l-lugha al-hadits. Kairo: Dar Gharib.

Fisiak, J. (1981). Contrastive Linguistics and The Language Teachers. Pergamon Press. Oxford.

Harbi, A.(2011). Articles-Verbal Modal. Majalah Humanities, 14(9).

Holes, C. (1995). Modern Arabic: Structures, functions, and varieties. London: Longman.

Ibrahim, S. (2007). At-Tafkïru 'ṣ-șautï wa 'n-nahwi: fi dau’i çilmi 'l-lu gaati 'l-hadïin. Kairo: Jämiçah țanța.

James, C. (1998). Contrastive analysis. London: Longman.

Lakoff, G. (1972). "Hedges: A Study in Meaning Criteria and the Logic of Fuzzy Concepts". Chicago Linguistic Society Papers, 8, 183-228.

Labov, W, \& Herzog, S. (1968). Sociolinguistics. Oxford: Blackwell.

Ma'ruf, A. (2011). The Role of Arabic Language in Cultural Construction Process. Arabic Language Teachers' Union in Indonesia, Ugi Arta: Fikr Publication.

Matthews, R. (2005). Modal Auxiliaries Constructions TAM and Interrogatives. In Fachinetti / Krug / Palmer(eds). London: Longman.

Nickel, G. (1971). Paper in Contrastive Linguistics. Cambridge. CUP.

Saeed, J. I. (2004). Semantics. Malden, MA: Blackwell.

Safi, A. B. (June 02, 2001). ARTICLES-Lexicalization and Modalization of Prepositions in English-Arabic Translation. International Journal of Arabic- English Studies. Vol.2, No. $1 \& 2$.

Wided, B. (2010). Dissertation: Modality in English, French, Arabic Biomedical Discourse: A Contrastive Study of Drug Information Leaflets. Al-Geria: Mentouri University. 